C O L A B O R A Ç Ã O E S P E C I A L

\title{
O MAL-ESTAR NO PATRIMÔNIO: IDENTIDADE, TEMPO E DESTRUIÇÃO
}

Heritage and its discontents: identity, time and destruction

\author{
JOSÉ REGINALDO SANTOS GONÇALVES
}

http://dx.doi.org/10.1590/S0103-21862015000100012

José Reginaldo Santos Gonçalves é professor titular do Departamento de Antropologia Cultural e do PPGSA do IFCS/UFRJ, e pesquisador do CNPq.

Texto recebido em 14 de maio e aprovado para publicação em 15 de maio de 2015.

Este texto foi originalmente elaborado como aula inaugural do Programa de Pós-Graduação em Bens Culturais da FGV. 


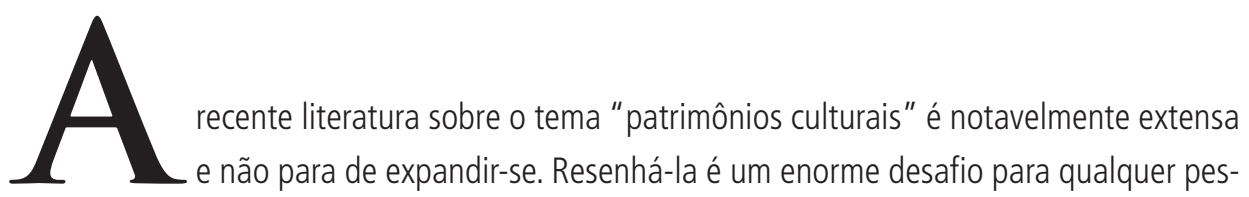
quisador. ${ }^{1}$ Essa produção repercute a crescente presença social e política dessa categoria desde as últimas décadas do século passado e sua relevância nas políticas públicas e no cotidiano de diversos segmentos sociais. Um historiador no ano 2115 provavelmente vai se perguntar por que as pessoas, na virada do século XX para o XXI, se mostravam tão sensibilizadas pelas palavras "patrimônio" e "memória" e tão obcecadas pelas ações de proteção e preservação de seus "bens culturais". Que ameaça assombrava seus corações e mentes? É provável que se pergunte também como essas atitudes preservacionistas podiam conviver com catástrofes naturais e sociais tão devastadoras como as que conhecemos no mundo contemporâneo e que atingem precisamente esses objetos que são alvo de incansáveis esforços de proteção e preservação. Como entender a lógica dessas ações destrutivas sobre as quais, aparentemente, não se conseguia exercer um eficaz controle coletivo?

Atualmente, qualquer objeto material, qualquer espaço, qualquer prática social, qualquer tipo de conhecimento pode ser identificado, celebrado ou contestado como "patrimônio" por um ou mais grupos sociais. Assim como já se diagnosticou um "abuso da memória" (Todorov, 2004), o mesmo se pode dizer a respeito dessa palavra complementar, o "patrimônio", e seu caráter inflacionário (Heinich, 2009). De modo voraz a categoria estende-se para diversos domínios, e, para além dos clássicos patrimônios históricos e culturais, encontram-se os etnológicos, ecológicos, entre outros. A categoria do "intangível", por sua vez, tornou possível "patrimonializar" uma vasta gama de itens e até mesmo "pessoas", como evidencia o projeto dos "tesouros humanos vivos", programa patrocinado pela Unesco que visa a proteger e preservar indivíduos que controlam determinados saberes tradicionais que estariam sob o risco de serem esquecidos (http://www.unesco.org/culture/ ich/es/tesoros-humanos-vivos).

Quais as razões desse incontrolável processo de expansão dos patrimônios no mundo contemporâneo? E, sobretudo, como entender, ao lado dessa obsessão preservacionista, a fúria destruidora que se abate sobre diversos bens culturais? 


\section{QUANDO PRECISAMOS DE UMA IDENTIDADE?}

Igumas categorias aparecem de modo recorrente nos discursos do patrimônio. Elas
mobilizam e dão direção aos empreendimentos de preservação dos diferentes patrimônios. Assim, é comum que se assuma como um dado que os patrimônios materiais ou imateriais expressam ou representam a "identidade" de grupos e segmentos sociais. Um tipo de arquitetura, assim como uma culinária, uma atividade festiva, uma forma de artesanato ou um tipo de música, pode ser identificado como "patrimônio cultural" na medida em que é reconhecido por um grupo (e eventualmente pelo Estado) como algo que lhe é próprio, associado à sua história e, portanto, capaz de definir sua "identidade". Defender, preservar e lutar pelo reconhecimento público desse patrimônio significa lutar pela própria existência e permanência social e cultural do grupo.

A partir dos anos 1980, o tema invadiu a agenda de diversos movimentos sociais. Se até aquela década, ao menos no contexto brasileiro, as discussões sobre o patrimônio restringiam-se à esfera do Estado e dos intelectuais que dirigiam as agências de preservação histórica, a partir de então o tema difundiu-se pela sociedade civil, sendo reinterpretado e utilizado por grupos e associações civis como um instrumento de luta política. A noção de "identidade" desempenha nesses processos um papel crucial.

Do ponto de vista do Estado e de suas políticas, especificamente suas políticas de patrimônio, "identificar" um grupo e seu patrimônio equivale a exercer positivamente sua função enquanto agência do poder. Por esse ângulo, a noção traz em si uma certa ambiguidade: se, por um lado, é a forma pela qual um grupo se afirma publicamente, por outro, é o modo pelo qual o Estado exerce seu controle sobre a sociedade. Segundo Michel Foucault,

a identidade é uma das primeiras produções do poder, desse tipo de poder que conhecemos em nossa sociedade. Eu acredito muito, com efeito, na importância constitutiva das formas jurídico-político-policiais de nossa sociedade. Será que o sujeito, idêntico a si mesmo, com sua historicidade própria, sua gênese, suas continuidades, os efeitos de sua infância prolongados até o último dia de sua vida etc., não seria o produto de certo tipo de poder que se exerce sobre nós nas formas jurídicas e nas formas policiais recentes? É necessário lembrar que o poder não é um conjunto de mecanismos de negação, de recusa, de exclusão. Mas, efetivamente, ele produz. Possivelmente produz até os próprios indivíduos (Foucault, 2006: 84).

Nesse sentido, os patrimônios são menos expressões de identidades do que meios de produção de determinadas formas de autoconsciência individual e coletiva. 0 debate sobre os patrimônios não deve, portanto, do ponto de vista analítico, limitar-se às tarefas de descobrir, defender e preservar "identidades" supostamente dadas. Essa noção deve ser 
problematizada, sendo necessário também, ao mesmo tempo, discutir a noção de "patrimônio", como ela emerge na história da modernidade e quais os perfis semânticos que ela veio a assumir. Por um lado, o "patrimônio" é uma categoria eminentemente ocidental e que acompanha a história dessa civilização (Hartog, 2003: 163-206). Mas, para que não pensemos a sua singularidade como um absoluto, talvez seja necessário reconhecer que, enquanto uma categoria, ela pode ser encontrada, de formas diferenciadas, em outras sociedades ou culturas. É possível contra-argumentar e dizer que isto significa levar longe demais o reconhecimento da sua presença. Mas, se contornamos essa discussão, o que importa efetivamente é explorar, comparativamente, as diferenças entre essas concepções.

Desse modo, o que está em jogo nesses contextos "não ocidentais" ou "não modernos", quando consideramos as "concepções nativas" de patrimônio, não é necessariamente a "identidade" dos povos e grupos sociais cujos objetos e modos de vida são alvos de processos de patrimonialização por agências ocidentais. Eles não estão, como os homens e as mulheres da modernidade ocidental, preocupados em buscar uma "identidade" que residiria no fundo de suas experiências individuais e coletivas. Pelo menos, não nos termos em que o Ocidente moderno formula e busca responder a essa questão. Trata-se, antes, da forma como esses povos e grupos se situam em suas relações com a ordem cosmológica, natural e social, preocupados em interagir com as diversas entidades do universo: os deuses, os mortos, os antepassados, os parentes, os vizinhos, os animais, as plantas etc. Do ponto de vista de suas cosmologias, eles existem individual e coletivamente na medida em que fazem parte dessa extensa rede de relações de troca. Nesse sentido, descobrir e defender sua "identidade" não é necessariamente, para eles, um problema. Esta é, na verdade, uma preocupação presente nos discursos e políticas de patrimônio que lhes são impostos quando, sempre com as melhores intenções, se busca preservar seu "patrimônio" e ainda classificá-lo como "patrimônio da humanidade". Vale assinalar, no entanto, que essa consciência da "identidade" não é inteiramente estranha à sua experiência e pode também ser partilhada por eles em diversas situações sociais. Isso acontece quando eles se apropriam dos modernos discursos e políticas de patrimônio e se organizam em movimentos sociais para defender o que chamam de sua "cultura", quando se organizam para construir museus que expressariam a sua "identidade" e sua "memória".

Assim, no contexto brasileiro das recentes políticas patrimoniais para as culturas populares, foi conduzido há alguns anos pelo IPHAN o processo de registro do "ofício" das "baianas de acarajé", o que levou ao seu reconhecimento jurídico como "patrimônio imaterial" (http://portal.iphan.gov.br/montarDetalheConteudo.do?id=17750\&sigla=Institucional \&retorno=detalhelnstitucional). Em seu livro Baianas de acarajé: comida e patrimônio no Rio de Janeiro (2011), Nina Pinheiro Bitar analisa esse processo de registro e explora o ponto 
de vista das "baianas" sobre sua transformação em "patrimônio imaterial". Um dos pontos centrais de sua análise consiste em mostrar que, do ponto de vista delas, sua atividade não se restringe a aspectos estritamente culinários, comerciais ou identitários. Ou seja: não se trata, estritamente falando, de um "ofício" ou da defesa de uma "identidade", mas de uma "obrigação", no sentido mágico e religioso. As baianas que aparecem nessa pesquisa entendem sua atividade como uma relação de dádiva e contra-dádiva com uma determinada entidade do candomblé: lansã. As atividades de preparação e de venda do acarajé permeiam essas relações. Os pontos de venda não são escolhidos arbitrariamente ou por razões comerciais, mas indicados ao indivíduo por essa divindade. A relação com parte da clientela confunde-se com a atividade dessas baianas enquanto pessoas "do santo". As relações que, no espaço público da cidade, elas estabelecem com mendigos, assaltantes, crianças de rua são pensadas a partir de categorias religiosas. Elas os classificam como o "povo da rua" e, como tal, são respeitados. A rua não é apenas o espaço da cidadania nem o espaço físico planejado pelos urbanistas. É também o universo de personagens ligados ao universo das religiões afro-brasileiras.

Assinale-se, no entanto, que essa concepção não impede que elas assumam positivamente sua condição de "patrimônio imaterial" e usem politicamente a noção de "identidade" para garantir sua reprodução no universo da rua, especialmente em oposição aos "camelôs". Elas afirmam: "agora que somos patrimônio..., não podemos ser tratadas como qualquer um. Não somos cozinheiras e nem camelôs, somos 'baianas de acarajé'" (Bittar, 2011).

Como vimos ao conduzir nossa observação para o interior desse universo sociocultural, constatamos que a noção individualizada de "identidade" perde sua centralidade, sendo substituída por uma autopercepção relacional definida pelas trocas com uma entidade religiosa. Nessas trocas importa não exatamente o produto acabado da atividade (o acarajé como um emblema da "identidade" desse grupo social ou sua atividade como um "ofício"), mas todo o extenso processo social de produção e consumo envolvendo a destruição ou transformação das matérias primas necessárias àquela atividade culinária. Nesse processo emergem as relações das "baianas" com os fornecedores dessas matérias primas, com seus clientes e com a entidade protetora. Já nas relações com o IPHAN e com outros órgãos do Estado, nas relações com associações civis, elas operam com categorias tais como "identidade", " ofício" e "patrimônio", usando-as como instrumentos para seu reconhecimento social e político.

\section{O PATRIMÔNIO E O TEMPO} discursos do patrimônio brasileiro, ela aparece de modo recorrente. Intelectuais como 
Rodrigo Melo Franco de Andrade (1898-1969) e Aloisio Magalhães (1927-1982), obcecados por uma "identidade nacional brasileira", defenderam de modo admirável o chamado patrimônio histórico e cultural brasileiro (Gonçalves, [1996] 2004; Fonseca, 1997 ; Rubino, 1991; Santos, 1992; Chuva, 2009). Em suas concepções, o patrimônio é percebido a partir de uma condição de possível "perda", cabendo às agencias de preservação resgatá-lo de um suposto processo de declínio e desaparecimento (Gonçalves, [1996] 2004). Nesses discursos, o patrimônio aparece como um dado individualizado, um objeto que pode ser nitidamente identificado, definido juridicamente e, portanto, preservado, embora sob a perene condição de possível perda de sua forma original ou de sua "autenticidade". Os que assumem esse discurso situam-se numa determinada concepção de tempo histórico, um tempo progressivo, no qual o futuro é um fim absoluto, percebendo-se o presente ora como uma fonte de destruição do passado (daí o risco da "perda"), ora como um campo de possibilidades para construir o futuro, em especial o futuro nacional.

É difícil encontrar essa obsessão por uma suposta "perda" nas concepções de patrimônio que comentávamos há pouco, entre as "baianas de acarajé". Em suas relações de dádiva e contradádiva com lansã, elas buscam assegurar bons resultados, mas não necessariamente preservar um patrimônio que estaria sob o risco de "perda". Em outras palavras, se é verdade que toda formação social partilha alguma concepção de patrimônio, esta não está necessariamente vinculada a uma busca de "identidade" nem associada a um sentimento de "perda". Essa obsessão parece ser uma singularidade do Ocidente moderno e, mais precisamente, de sua concepção de "tempo histórico".

Ao explorarmos os usos sociais dessas categorias, podemos elaborar um entendimento do "patrimônio" que nos permitirá transitar entre os diferentes universos socioculturais, entre os diferentes perfis semânticos que essa categoria pode assumir, seja historicamente, seja geograficamente. Uma hipótese para viabilizar essa tradução consiste em pensar os patrimônios como sistemas de relações sociais e simbólicas capazes de operar uma mediação sensível entre o passado, o presente e o futuro (Gonçalves, 2010). Essa hipótese encontra sustentação nos estudos produzidos pelo historiador François Hartog, que tem se dedicado a refletir sobre os recentes processos de transformação em nossos modos de experimentar o tempo e suas repercussões na produção historiográfica e, especificamente, nos discursos do patrimônio (Hartog, 2003). Os patrimônios são percebidos como "sintomas" de nossas experiências do tempo: ao descrever e analisar suas variações históricas e geográficas, estaríamos na verdade comparando formas diversas de se experimentar o tempo (Hartog, 2003). Para ele, a expansão extraordinária dos patrimônios no mundo contemporâneo deve ser entendida como o sintoma de uma crise nas formas como experimentamos as relações entre passado, presente e futuro. 
Essa expansão consiste na crise de um determinado "regime de historicidade", o regime "modernista" ou "futurista", que se caracteriza pela valorização positiva do "futuro". Esse regime estaria, de certo modo, sendo substituído por um outro, no qual o "presente" é fortemente valorizado: o regime "presentista" (Hartog, 2003). Nesse novo regime, o passado seria obsessivamente reproduzido como objeto de fruição, mas não como base para uma projeção positiva no futuro.

Nessa perspectiva, aquilo que chamamos de "tempo histórico", o tempo representado como uma flecha cuja ponta está projetada no futuro, não seria algo natural, mas sim uma categoria sujeita, ela própria, a transformações históricas. A moderna concepção do tempo histórico emerge a partir do século XVIII e se contrapõe ao "regime clássico" de representação do tempo. Neste último, se reconhecia uma continuidade entre o passado, o presente e o futuro, e por isso mesmo o passado era visto como fonte de iluminação, como um guia para a vida presente, e a história podia então ser considerada como "mestra da vida" (Hartog, 2003: 11-32). Já o regime moderno de representação do tempo histórico toma como ponto de partida uma assimetria entre o passado e o presente. 0 passado passa a ser considerado um universo obscuro do qual não emanaria nenhuma luz sobre o presente. Não por acaso, a noção moderna de patrimônio (juntamente com os Estados nacionais) juntamente com o sentimento coletivo de que esse patrimônio estava sob ameaça de destruição emergiram nesse contexto de final do século XVIII e final do século XIX (Fumaroli, 1997: 101-116; Harrison, 2013: 42-67).

0 regime "presentista" representa, para Hartog, uma crise dessa valorização positiva do futuro e, consequentemente, uma ênfase excessiva no presente. 0 futuro vem a ser inibido em favor de um passado que invade o presente na forma de "patrimônios", ou na forma de objetos e formas de vida que são colecionados e expostos em museus e em espaços musealisados das cidades, para serem apreciados e consumidos num presente que se configura como eterno (Hartog, 2003: 207-218).

Essa crise em nossa experiência moderna do tempo já havia sido assinalada por Lévi-Strauss, que, numa entrevista nos anos 1980, chamava a atenção para o fato de que as sociedades ocidentais vinham experimentando o que ele chamou de "resfriamento" do tempo. Nossa obsessão pelos patrimônios estaria associada, segundo ele, a essas transformações no modo como representamos o tempo:

Às nossas sociedades, responsáveis ou vítimas de tragédias horríveis, aterrorizadas pelos efeitos da explosão demográfica, o desemprego e outros males, um apego renascente ao patrimônio, o contato que se esforçam para retomar com suas raízes [...] dariam a ilusão, como a outras civilizações ameaçadas, que elas podem - de maneira totalmente simbólica, é óbvio - contrariar o curso da história e suspender o tempo (Lévi-Strauss, 1983: 9-10). 
O florescimento extraordinário das diversas modalidades de patrimônios culturais na atualidade, nosso curioso empenho em preservar ou reconstruir objetos, lugares, prédios e formas de vida associadas ao passado talvez revele mais do que um esforço coletivo de buscar e expressar o reconhecimento de "identidades" sociais contra os supostos riscos de sua "perda". É provável que esteja em jogo um trabalho coletivo de mediar e equilibrar contradições em nosso modo contemporâneo de representar o tempo, uma concepção na qual o futuro já não brilha como o foco das esperanças utópicas, e o passado é preservado ou reconstruído na vã expectativa de parar o tempo.

Os patrimônios podem simultaneamente servir aos propósitos da indústria turística em escala planetária, às estratégias de construção de "identidades", à formação de subjetividades individuais e coletivas, às reinvindicações de natureza política e econômica por parte de grupos sociais, ou ainda a políticas de Estado. Mas em todos esses usos do patrimônio é possível perceber determinados modos de imaginar e gerir as relações entre passado, presente e futuro.

Ao nos referirmos às essas formas de experiência do tempo, vale lembrar que o patrimônio cultural brasileiro, enquanto discurso e enquanto política de Estado, emergiu, ainda nos anos 1930, sob a inspiração de intelectuais modernistas: Mário de Andrade, Rodrigo Melo Franco de Andrade, Gilberto Freyre, entre outros. Em contraste com a vanguarda europeia, o modernismo brasileiro, na perspectiva de alguns analistas, distingue-se por uma tendência conservadora que, ao invés de celebrar a ruptura, concilia passado, presente e futuro. Observe-se que alguns dos intelectuais que estiveram à frente da construção do patrimônio no Brasil e dirigiram a criação e o funcionamento do então SPHAN foram também responsáveis pelo projeto e a construção de Brasília (Chuva, 2009). Um historiador, refletindo sobre a história da arquitetura moderna no Brasil, assinala:

Terminou o século XX, e Brasília (...) continua sendo sua cidade mais moderna; tão moderna que o traçado fundacional (o chamado Plano Piloto) foi declarado "patrimônio histórico da humanidade", para que seu caráter moderno seja preservado da passagem do tempo. De fato, Brasília não é somente a cidade mais moderna no século XX, mas, fundamentalmente, é um museu da modernidade, numa época em que a mera passagem do tempo, o atual, não é moderna e que o moderno deve ser preservado (Gorelik, 2005: 151).

Mas se o tempo atual não é mais "moderno", que tempo é esse? Qual a forma de representação desse tempo? Como experimentamos, na atualidade, as relações entre passado, presente e futuro? Que transformações ocorrem na sensibilidade coletiva, especialmente nas últimas décadas do século XX e na virada para o século XXI, que teriam alterado as atitudes 
e representações em relação aos patrimônios no Brasil? Se as atitudes e representações modernistas buscavam recuperar a história e a memória com a finalidade de construir um futuro, que atitudes podemos surpreender nas últimas décadas?

Os intelectuais modernistas que, no Brasil, estiveram associados ao patrimônio tinham em vista a construção do futuro da nação e recorriam ao passado como uma fonte de inspiração para o presente. Em um de seus textos sobre o patrimônio e a identidade nacional brasileira, ainda nas primeiras décadas do IPHAN, Rodrigo Melo Franco de Andrade afirmava: "A verdade é que não somos ainda" (Gonçalves, 2004: 115). 0 esforço coletivo de construção do patrimônio, dirigido pelo Estado, estava justificado por esse projeto de construção de uma identidade nacional que, supostamente, ainda não existia. Décadas depois, já nos anos 1970, Aloísio Magalhães, embora operando com uma outra narrativa do patrimônio, tinha ainda como horizonte de expectativa o futuro de uma nação discursivamente construída a partir de sua "diversidade cultural" (Gonçalves, 2004). Ambos operavam num regime "moderno" ou "futurista" de representação do tempo, para usarmos aqui as categorias analíticas de Hartog (2003).

Outro aspecto a se destacar no contexto brasileiro é o fato de os intelectuais que se dedicaram ao patrimônio estarem situados no aparelho de Estado, o qual desempenhava um papel central na construção de uma identidade brasileira. A expansão recente do patrimônio está articulada a uma série de transformações nos últimos 30 anos. No plano institucional, constata-se que o Estado nacional, que durante décadas operou com certa exclusividade na elaboração e implementação das políticas de patrimônio, já não detém a mesma hegemonia. Organizações não governamentais, movimentos sociais, empresas, grupos sociais e indivíduos assumem iniciativas no sentido de reivindicar, estabelecer e contestar "patrimônios culturais". Sem deixar de ser uma agência legitimadora e apoiadora fundamental, o Estado se vê obrigado a reconhecer e a lidar com uma série de outros atores sociais engajados na identificação e preservação de patrimônios (Gonçalves, 2012).

Ao lado dessa mudança na configuração institucional, assiste-se a uma fragmentação na produção dos patrimônios, que repercute no plano discursivo. Se até os anos 1980 as narrativas estavam voltadas firmemente para a nação, e todo e qualquer bem tombado 0 era em função de seus vínculos com a história e a identidade nacional, nas últimas décadas, desde então patrimônios associados a diversos grupos e movimentos sociais vêm sendo reivindicados, reconhecidos ou contestados sem que os vínculos com uma "identidade nacional" sejam necessariamente colocados em primeiro plano. Observa-se uma desestabilização das concepções de patrimônio centradas na história e na identidade nacional. Até meados da penúltima década do século XX, o vocabulário da história, e especialmente da história da arte e 
da arquitetura, eram centrais na construção discursiva do patrimônio. Nas últimas décadas do século XX, acompanhando a emergência dos "patrimônios imateriais", assistiu-se a uma intensificação dos usos do vocabulário da moderna antropologia social e cultural. A "concepção antropológica de cultura" tornou-se também, a exemplo do "patrimônio", um outro "grito de guerra" na luta pelo reconhecimento e pelo registro de "culturas populares".

0 mercado, seja como adversário, seja como aliado, sempre esteve presente, de modo implícito ou explícito, nos discursos e políticas de patrimônio. Mas nas últimas décadas é possível perceber uma intensificação dessas relações, especialmente no que se refere ao turismo. Assim, cada lugar que vem a ser oficialmente reconhecido como "patrimônio" já é ou torna-se rapidamente uma "atração turística" (Kirschenblatt-Gimblett, 1998). Observa-se a existência de uma extensa rede de mercado associada aos discursos e políticas do patrimônio: companhias de transporte, redes de hotéis e restaurantes, visitações turísticas, festivais, comércio de souvenirs (postais, reproduções, fotografias, filmes, objetos), edição e circulação de jornais, revistas, livros. Curiosamente, nos discursos modernistas do patrimônio, o turismo sempre foi classificado como uma fonte de perigo, algo que deveria ser mantido à distância, na medida em que se pretendesse que o patrimônio não perdesse sua "autenticidade". Se uma determinada concepção de "autenticidade" estava associada à hegemonia e à centralidade do Estado nacional na formulação e implementação de políticas de patrimônio, essa concepção parece alterar-se em função da nova configuração institucional que vem se desenhando a partir das últimas décadas do século XX. Na atualidade, esses discursos parecem evidenciar concepções de "autenticidade" em que a ênfase é colocada não mais exclusivamente numa relação orgânica com o passado nacional, mas na própria possibilidade presente (ou "presentista") de reprodução social de diversos passados. 0 patrimônio oscila entre a história nacional e as memórias coletivas.

Os intelectuais que pensavam, e os que ainda pensam, em termos de uma "retórica da perda" postulam a existência de um "objeto de desejo", seja o "passado nacional", seja a "cultura popular", seja o "folclore", cuja busca revelaria a face autêntica do Brasil. Expressão de um "regime moderno de historicidade" (Hartog, 2003), a "retórica perda", em seu declínio no atual contexto marcado pelo regime "presentista", mostra-se como uma modalidade entre outras de representação do patrimônio, originalmente acoplada a um contexto institucional e a um certo regime de representação do tempo. Desse modo, é possível pensar o patrimônio não apenas como algo situado num tempo ou num espaço distante e inalcançável, mas também como um processo presente, incessante, conflituoso e interminável de reconstrução.

Assinale-se que no coração desses discursos, juntamente com a noção de "perda", insinua-se o espectro da "destruição", contra a qual se posicionam os esforços coletivos no sentido de proteger e preservar os bens culturais ameaçados. Essa destruição, no entanto, é 
projetada para fora dos limites do discurso patrimonial, sendo percebida como algo externo, algo que ameaça de fora os bens materiais e imateriais visados por esse discurso. Ela pode assumir formas naturais (intempéries, catástrofes) ou sociais e históricas (guerras, atentados, o simples abandono dos bens culturais, a indiferença da população ou dos governantes), mas configura-se sempre como uma espécie de inimigo externo a ser combatido. No entanto, podemos perguntar em que medida esse inimigo não convive internamente com as próprias práticas da preservação, não somente enquanto ameaça, mas simultaneamente como fonte de criação. Sendo assim, no ato mesmo da preservação seria necessário observar o que é necessariamente destruído ou esquecido.

\section{A Destruição COMO CATEGoria POSITIVA}

"destruição" pode evidentemente assumir vários perfis semânticos. Há formas de imainterna ao processo de preservação e não como algo externo e perigoso a ser evitado e combatido. É quando podemos perceber uma espécie de destruição domesticada, onde a noção de "perda" não mais assume um papel central.

No noroeste da África, os Batamaliba são conhecidos pela sua arquitetura singular. Suas casas são especialmente apreciadas, no Ocidente, pela sua forma estética. Há alguns anos, a Unesco tombou muitas dessas casas como "patrimônio da humanidade" (http://whc.unesco. org/en/list/1140). Ocorre no entanto que, do ponto de vista nativo, as concepções de casa e de arquitetura não coincidem com as concepções ocidentais. Esse fato fica evidente em um estudo produzido pela antropóloga Suzanne Blier que explora a cosmologia subjacente a essa arquitetura (Blier, 1987). Primeiramente, as casas são construídas para abrigar famílias extensas. Além disso, são pensadas pelos Batamaliba como seres vivos. Eles as descrevem usando como referência as diversas partes e o funcionamento do corpo humano: uma casa tem cabeça, pernas, braços, boca, partes sexuais etc. Ela deve ser cuidada, alimentada, protegida, como qualquer ser humano. Cada uma das casas tem uma biografia que se confunde com a biografia do homem mais velho da família. Quando este morre, a casa tem necessariamente de ser demolida. Algumas de suas partes são usadas para os descendentes construírem uma nova casa.

Pensar a casa como uma entidade viva, semelhante a um ser humano, dotada de órgãos e de uma força vital como aquela que é encontrada nos seres humanos, é algo comum a muitas das chamadas sociedades primitivas e se faz presente também, embora de forma diferenciada, nas grandes civilizações tradicionais. ${ }^{2}$ Em termos esquemáticos, podemos dizer que, nesses contextos, a "arquitetura" é pensada como uma atividade que pressupõe conexões vivas com 
o cosmo, com a natureza, com a sociedade, com a biografia e com o corpo dos indivíduos. Para esses povos, aquilo que nós ocidentais chamamos de "arquitetura" não é imaginado como algo que se define exclusivamente pela sua forma técnica ou utilitária (um abrigo contra as intempéries e contra os animais), nem exclusivamente pela sua forma estética, pelo seu estilo. Trata-se de uma forma total, e, portanto, os homens e mulheres que as habitam na verdade estão habitando o cosmo, uma vez que cada casa é construída como uma espécie de microcosmo do universo. Em resumo, a casa é uma representação sensível da ordem universal, como sugerem os estudos clássicos de Marcel Mauss (2003) e de Pierre Bourdieu (1972), respectivamente sobre os Inuit, no noroeste americano, e sobre os Kabila no norte da Argélia.

Diante desses fatos, cabe a pergunta: como preservar essas casas como "patrimônio", nos termos em que os representantes da Unesco entendem essa categoria? Afinal, para os Batammaliba, sua concepção de patrimônio inclui necessariamente a construção, a manutenção e a destruição ritual da casa. Esse processo é equivalente ao nascimento, à formação e à morte de um ser humano e, portanto, implica a geração e os cuidados com a casa enquanto ser vivo, considerando-se, nesse processo, também a sua morte ritualmente elaborada.

Muitos autores têm recentemente chamado a atenção para a "materialidade" de objetos e espaços, mostrando que estes não funcionam apenas como "suportes", mas também como meios de produção de formas de autoconsciência individual e coletiva (Appadurai, 2009; Küchler, 2002; Miller, 2005; Tilley, Keane, Küchler, Rowlands e Spyer, 2006; Wagner, 2010; Gonçalves, Guimarães e Bitar, 2013). ${ }^{3}$ Alguns autores têm assinalado o "poder de agência" dos objetos materiais, chamando a atenção para o fato de que estes são capazes de desencadear efeitos na vida social (Gell, 1998). No contexto da modernidade ocidental, a destruição desses objetos e espaços aparece usualmente como algo externo à sua produção. No entanto, sabemos que objetos materiais, prédios e espaços classificados como "patrimônios" podem, ao mesmo tempo, ser alvo de um intenso e amoroso cuidado de preservação e de uma hostilidade avassaladora. São numerosos os casos de objetos, prédios e lugares destruídos em função do ódio religioso e político. Essa hostilidade é evidente no noticiário da mídia, e sua presença já inspirou reflexões sobre o ódio declarado e a atitude destrutiva frente a imagens negativamente classificadas em termos religiosos. Muitos estudos assinalam a ambivalência dessas atitudes iconoclastas, nas quais aqueles mesmos que destroem as imagens são, antes de mais nada, os que se sentem por elas ameaçados, reconhecendo-Ihes assim implicitamente seu poder, a despeito de negarem violentamente esse fato (Latour, 2002 e 2009; Gamboni, 1997; Nelson e Olin, 2003).

Mesmo os discursos articulados pela "retórica da perda", conforme já tive oportunidade de assinalar, convivem com uma "perda" que é assumida como um dado, mas que na 
verdade é uma construção, onde se postula a existência de uma ameaça aos bens culturais, o que leva consequentemente a concentrar os esforços no trabalho positivo da preservação. Mas, afinal, para quem a destruição de um prédio histórico deve aparecer como uma "perda"? Sem que isto signifique necessariamente a expressão de um relativismo extremado, quero acentuar que, menos que um dado natural ou social, a chamada perda decorre de um determinado "regime de historicidade" (Hartog, 2003), de um determinado modo de narrar e construir o passado (Gonçalves, 2004).

Acrescente-se que o uso dessa categoria se faz presente também num certo modo de conceber as relações entre memória, identidades e objetos materiais. Nesta concepção, a permanência desses objetos levaria necessariamente à permanência da memória e da identidade, enquanto sua destruição levaria ao esquecimento. Pressupõe-se uma necessária associação entre memória e seus suportes materiais, os quais deveriam ser preservados para que aquela se conservasse. Alguns autores têm recentemente problematizado essa relação, mostrando que não necessariamente a preservação, mas muitas vezes a destruição de objetos e espaços materiais pode ser o elemento gerador de identidades e memórias. A arte da memória transforma-se numa "arte do esquecimento" (Forty e Küchler, 1999; Küchler, 2002; Weinrich, 2001). Num estudo sobre objetos rituais que, na Melanésia, demarcam o fim de um período de luto pelos mortos, Susanne Küchler mostra que, logo em seguida ao seu uso ritual, esses objetos (malanggan: imagens representando indivíduos falecidos) são abandonadas para serem destruídos pelas intempéries (Küchler, 1999 e 2002). Nenhum cuidado de conservação Ihes é reservado, uma vez que a memória desses mortos não está situada neles, mas sim nas elaborações narrativas dos indivíduos sobre o cerimonial. Apenas uma imagem mental é preservada. Segundo essa autora:

Os malanggan documentam assim um determinado modo de esquecimento, um modo que é desencadeado ao se tornarem invisíveis as representações que operam como veículos de transmissão social. Uma vez invisíveis e publicamente esquecidos, o malanggan forma o recurso gerador e reprodutor de uma economia informacional na qual os direitos de propriedade incidem não sobre os objetos, mas sobre os seus 'resquícios' mentais (Küchler, 1999: 68). ${ }^{4}$

Diversamente do nosso modo de entender as relações entre memória e objetos materiais, onde estes são vistos como garantidores da permanência da memória e suas imagens, os usuários melanésios dos malanggan percebem essa relação a partir de uma separação entre imagem e objeto material (Küchler, 2002: 191). Altamente valorizados no mercado ocidental de "arte primitiva", abastecendo colecionadores e museus, esses objetos esculpidos em madeira e com vida efêmera vêm a assumir funções estéticas e de exibição museológica. Mas em 
seu contexto original, onde, diferentemente dos nossos museus, eles existem precisamente pela ausência destes, como distinguir, nas relações que os indivíduos mantêm com tais objetos, o trabalho coletivo de esquecimento e o trabalho de memória?

Essa ambivalência vem sendo explorada em contextos ocidentais através de estudos recentes que analisam os significados dos trabalhos de destruição na arquitetura e na preservação histórica, mostrando como as práticas técnicas e rituais de demolição estão intimamente associadas à construção e à preservação. Focalizando as dimensões técnicas e rituais das práticas de demolição, esses estudos mostram que a chamada destruição, longe de ser uma prática simples e imediata, na verdade supõe um complexo sistema de relações sociais e de categorias, sem as quais ela não se realiza (Goyena, 2011 e 2015). Quanto ao uso cotidiano de objetos materiais, outros estudos assinalam o quanto ele está associado ao trabalho de destruição e transformação desses objetos, o que desestabiliza sua visão usual enquanto realidades estáveis e enquanto suportes de identidades igualmente estáveis (Ingold, 2000 e 2011).

\section{Civilização E BARbÁRie}

$\mathrm{O}$ que podemos assinalar a partir desse conjunto de observações é o fato de que os trabalhos de esquecimento e destruição apresentam-se como elementos positivos e decisivos na produção da memória. 0 leitor deve lembrar-se de que em 0 mal-estar na civilização Freud defende a tese de que a civilização cobra um alto preço aos indivíduos: nada mais, nada menos do que a renúncia à satisfação de seus instintos mais elementares, entre eles a agressividade e a capacidade de destruição. Essa renúncia, sempre ambivalente, levaria a um perene mal-estar (Freud, [1930] 2010). Certamente não é meu propósito trazer uma hipótese psicanalítica para entender o patrimônio. No máximo, exploro uma analogia, uma vez que essa tese, para além dos círculos psicanalíticos, parece insinuar-se nos discursos e nas práticas sociais dos agentes envolvidos com patrimônios e museus. Resultado de uma luta interminável entre instinto de vida e instinto de morte, entre nossa capacidade de construir e nossa capacidade de destruir, o "mal-estar" que Freud diagnosticou como intrínseco à civilização remete a um difuso sentimento entre aqueles que, de algum modo, atuam na proteção, na preservação ou na destruição dos patrimônios. As práticas amorosas da preservação parecem conviver intensa e necessariamente com o ódio e a destruição. Estes, quanto mais intensamente combatidos, mais presentes se fazem, de modo explícito ou implícito.

Naturalmente vêm à nossa mente imagens muito recentes veiculadas pelos meios de comunicação, nas quais militantes do Estado Islâmico, em fevereiro de 2015, destroem peças assírias em um museu em Mosul no Iraque; e nas quais, em março do mesmo ano, o mesmo 
grupo jihadista destrói, também no Iraque, o sítio arqueológico assírio de Nimrud datado de 13 mil anos antes de Cristo (http://noticias.uol.com.br/ultimas-noticias/efe/2015/03/05/ estado-islamico-destroi-sitio-arqueologico-do-seculo-xiii-ac-no-iraque.htm). Nos anos recentes, Síria e Iraque têm sido o palco de uma notável expansão dessas atividades criminosas, que geram lucros para grupos envolvidos nessas guerras. No mês de abril de 2015, um jornal da ONU no Brasil trazia a seguinte manchete: "Destruição e tráfico de bens culturais atingiram uma escala sem precedentes" (http://nacoesunidas.org/unesco-destruicao-e-trafico-culturais-atingiram-uma-escala-sem-precedentes/). A notícia focalizava especialmente Síria e Iraque. Mas em diversos meios de comunicação é possível acessar notícias numerosas a respeito de incidentes similares em diversas partes do planeta. As narrativas que a mídia nos oferece apresentam um quadro confortável, onde a "civilização" está situada do nosso lado, e a "barbárie", evidentemente, fora dos nossos limites. Mas em que medida essas práticas, odiosas e merecedoras da condenação internacional, não estariam revelando uma espécie de "lado escuro da lua", algo presente, sutil ou ostensivamente, em nosso próprio cotidiano e que evitamos reconhecer? Não seriam ódio e destruição partes inerentes aos discursos e políticas de patrimônios e museus? Não seriam os bens classificados nessa categoria e abrigados nessas instituições também resultados de atos de ódio e destruição?

Embora possamos situar esses sentimentos coletivos como dados externos, como algo que nos atinge "de fora", sua presença persistente no campo dos patrimônios e dos museus nos leva a suspeitar de que esta seja mais uma de nossas cômodas ilusões. Numa paráfrase de Walter Benjamin, para quem não havia documento de civilização que não fosse também um documento de barbárie (Benjamin, 1985: 225), talvez não haja processo de patrimonialização (e de musealização) sem alguma forma de descarte e destruição. Caberia ao pesquisador, para entender de modo mais sistemático o campo dos patrimônios e dos museus, dedicar tanta atenção às práticas de preservação quanto ao seu avesso, as práticas de destruição, as quais acompanham as primeiras como uma sombra. Se assim procedemos, é possível perceber que a noção mesma de "identidade" não apresenta de fato a estabilidade e a coerência que muitas vezes lhes é atribuída. Os objetos e espaços materiais que a "representam" não conhecem necessariamente a solidez e a determinação que lhes atribuímos, uma vez que, ao serem construídos, usados, reconstruídos e preservados, sofrem simultaneamente os efeitos constantes da destruição, na medida mesmo em que são permanentemente transformados (Ingold, 2000 e 2011). Nos processos de produção social das identidades, estas não resultam de um exclusivo trabalho coletivo de construção e preservação, uma vez que as práticas de destruição Ihes são igualmente indispensáveis. No plano individual ou coletivo, somos, antes de tudo, o que esquecemos e descartamos. 


\section{NotAS}

1 Para uma apreciação dos contextos francês e anglo-americano, ver Nora (1997, 1997a), Hartog (2003), Leniaud (2002, 2013), Smith (2006), Benton (2010), Gillman (2010), Harrison (2010, 2013), Assmann (2011), Smith (2006), Heinich (2009), e Olick, Vinitzky-Serouss e Levy (2011). Para o contexto brasileiro, ver, entre outros, Arantes (1984, 2000), Abreu e Chagas (2010), Abreu, Chagas e Santos (2007), Lima Filho, Eckert e Beltrão (2007), Tamaso e Lima Filho (2012), e Gonçalves, Bitar e Guimarães (2013).

2 Exemplos semelhantes são encontrados numa outra área etnográfica, no Sudeste Asiático, num grupo cuja arquitetura foi estudada pela antropóloga Roxana Waterson: The living house: an anthropology of architecture in South-East Asia (2000).

3 Para uma interessante problematização das recentes teses sobre a categoria "materialidade", ver Ingold (2011: 19-32).

4 " Malanggan thus documents a mode of forgetting, a mode brought about through rendering invisible the representations that act as temporary vehicles of social transmission. Once invisible and publicly forgotten, malanggan forms the generative and reproductive resource of an information-based economy in which the proprietary right pertain not to objects, but to their mental 'remains'." (Küchler: 68).

\section{REFERÊNCIAS BIBLIOGRÁFICAS}

ABREU, Regina \& CHAGAS, Mário (orgs.). Patrimônio e memória: ensaios contemporâneos. Rio de Janeiro: Lamparina, 2010 [2003].

\& SEPULVEDA, Myrian (orgs). Museus, coleções e patrimônios: narrativas polifônicas. Rio de Janeiro: Iphan/ Garamond. 2007, Col. Museu, Memória e Cidadania.

APPADURAI, Arjun. A vida social das coisas: a mercadoria sob uma perspectiva cultural. Niterói: Eduff 2009.

ARANTES, Antonio Augusto. Produzindo o passado: estratégias de construção do patrimônio cultural. São Paulo: Brasiliense, 1984.

Paisagens paulistanas: transformações do espaço público. Campinas: Unicamp, 2000.

ASSMANN, Aleida. Cultural memory and western civilization. Functions, media, archives. Cambridge University Press, 2011.

BENJAMIN, Walter. Walter Benjamin: obras escolhidas. São Paulo: Brasiliense, v. I, 1985.

BENTON, Tim (ed.). Understanding heritage and memory. Manchester University Press, 2010.

BITAR, Nina. Baianas de acarajé: comida e patrimônio no Rio de Janeiro. Rio de Janeiro: Aeroplano, 2011.

BLIER, Suzanne. The anatomy of architecture: ontology and metaphor in Batammaliba

architectural expression. Cambridge University Press, 1997.

BOURDIEU, Pierre. La maison Kabyle ou le monde renversé. In: Esquisse d'une théorie de la pratique. Paris: Librairie Droz, 1972, p. 45-70.

CHUVA, Marcia. Os arquitetos da memória: sociogênese das práticas de preservação do patrimônio cultural no Brasil. Rio de Janeiro: Editora UFRJ, 2009. 
FUMAROLI, Marc. Jalons pour une hisotoire littéraire du patrimoine. In: NORA, Pierre (org.). Science et conscience du patrimoine. Paris: Fayard, 1997.

FONSECA, Maria Cecília Londres. O patrimônio em processo: trajetória da política federal de preservação no Brasil. Rio de Janeiro: Ed. UFRJ/MINC-IPHAN, 1997.

FOUCAULT, Michel. Sou um pirotécnico. In: POL-DROIT, Roger (org.). Michel Foucault: entrevistas. Rio de Janeiro: Graal, 2006, p. 67-102.

FORTY, Adrian \& KUCHLER, Susanne (orgs.). The art of forgetting: materializing culture. Oxford: Berg, 1999.

GAMBONI, Dario. The destruction of art: iconoclasm and vandalism since the French Revolution. London: Reaktion Books, 1997.

GELL, Alfred. Art and agency: an anthropological theory. Oxford: Clarendom Press, 1998.

GILLMAN, Derek. The idea of cultural heritage. Cambridge University Press, 2010.

GORELIK, Adrian. Das vanguardas a Brasília: cultura urbana e arquitetura na América Latina. Belo Horizonte: Ed. UFMG, 2005.

GONÇALVES, José Reginaldo Santos. A retórica da perda: discurso nacionalista e patrimônio cultural no Brasil. Rio de Janeiro. Editora da UFRJ, 2004 [1996].

. Os limites do patrimônio In: LIMA FILHO, Manuel Ferreira, ECKERT, Cornelia \& BELTRÃO, Jane (orgs.). Antropologia e patrimônio cultural: diálogos e desafios contemporâneos. Blumenau. ABA, Nova Letra, 2007. Antropologia dos objetos: patrimônios, museus e coleções. Brasília: IBRAM, 2007.

. Os patrimônios e o tempo. Ciência Hoje. Revista de Divulgação Científica da SBPC. Suplemento Trimestral. Rio de Janeiro, abril 2010.

. As transformações do patrimônio: da retórica da perda à reconstrução permanente. In: TAMASO, Izabela \& LIMA FILHO, Manuel Ferreira. Antropologia e patrimônio cultural: trajetórias e conceitos. Brasilia: ABA Publicações, 2012,p. 59-74.

__ GUIMARÃES, R. \& BITAR, N. (orgs.). A alma das coisas: patrimônios, materialidade e ressonância. Rio de Janeiro: Mauad/FAPERJ, 2013.

GOYENA, Alberto. Architecture inside out: urban transformations through the perception of demolition engeneers. Vibrant, 2011, v. 8, n. 2. Disponível em: http://www.vibrant.org.br/issues/v8n2/alberto-goyena-architecture-inside-out/.

. A demolição em 7 obras: arquitetura, patrimônio e esquecimento (tese de doutorado). Rio de Janeiro, PPGSA/IFCS/UFRJ, 2015.

HARRISON, Rodney. (ed.). Understanding the politics of heritage. Londres: Routledge, 2010.

—. Heritage: critical approaches. Londres: Routledge, 2013.

HARTOG, François. Régimes d'historicité: présentisme et expériences du temps. Paris: Seuil, 2003.

HEINICH, Nathalie. La fabrique du patrimoine: de la cathédrale à la petite cuillère. Paris: Maison des Sciences de l'Homme, 2009.

INGOLD, Tim. The perception of the environment: essays in livelihood, dwelling and skill. Londres e Nova York: Routledge, 2000. 
JosÉ REgINALDo SANTOS GONÇALVES

Being alive: essays on movement, knowledge and description. Londres e Nova York: Routledge, 2011.

KIRSHENBLATT-GIMBLETT, Barbara. Destination culture: tourism, museums, and heritage. Berkeley: University of California Press. 1998.

KÜCHLER, Susanne. The place of memory. In: FORTY, Adrian \& KÜCHLER, Susanne (orgs.). The art of forgetting: materializing culture. Oxford: Berg, 1999.

—. Malanggan: art, memory, and sacrifice. Oxford: Berg, 2002.

LATOUR, Bruno. Iconoclash: beyond the image wars in science, religion, and art. Cambridge: MIT Press, 2002.

Sur le culte moderne des dieux faitiches. Paris: La Découverte, 2009.

LENIAUD, Jean-Michel. Les archipels du passé: le patrimoine et son histoire. Paris: Fayard, 2002.

. Droit de cité pour le patrimoine. Paris: Presses Universitaires de France, 2013.

LÉVI-STRAUSS, Claude. Un autre régard. L'Homme, Paris, 1983,. 33, n. 126, p. 9-10.

LIMA FILHO, Manuel Ferreira, ECKERT, Cornelia \& BELTRÃO, Jane (orgs.). Antropologia e patrimônio cultural: diálogos e desafios contemporâneos. Blumenau: ABA, Nova Letra, 2007.

MILLER, Daniel (ed.). Materiality. Durham and London: Duke University Press, 2005.

MAUSS, Marcel. Sociologia e antropologia. SãoPaulo: Cosac\&Naif, 2003.

NELSON, Robert S. \& OLIN, Margaret (eds). Monuments and memory, made and unmade. Chicago: Chicago University Press, 2003

NORA, Pierre. Les lieux de mémoire, v. I. Paris: Gallimard, 1997.

. Science et conscience du patrimoine. Paris: Fayard, 1997a.

OLICK, Jeffrey K, VINITZKY-SEROUSSI \& LEVY, Daniel. The collective memory: a reader. Oxford University Press, 2011.

RUBINO, Silvana. As fachadas da história: os antecedentes, a criação e os trabalhos do Serviço do Patrimônio Histórico e Artístico Nacional, 1937-1968. (Dissertação de Mestrado). Universidade de Campinas. 1991.

SANTOS, Marisa Veloso Motta. O tecido do tempo: a ideia de patrimônio cultural no Brasil. (Tese de doutorado). Brasília, Departamento de Antropologia, Universidade de Brasília. 1992.

SMITH, Laurajane. Uses of heritage. Londres e Nova York: Routledge, 2006.

TAMASO, Izabela \& LIMA FILHO, Manuel Ferreira. Antropologia e patrimônio cultural: trajetórias e conceitos. Brasilia: ABA Publicações, 2012.

TILLEY, C.; KEANE, W.; KÜCHLER, S.; ROWLANDS, M. \& SPYER, P. (eds.). Handbook of material culture. London: Sage, 2006.

TODOROV, Tzvetan. L'abus de la mémoire. Paris: Arléa, 2004.

WATERSON, Roxana. The living house: an anthropology of architecture in South East Asia. Tokyo: Tutle Publishing, 2000.

WEINRICH, Harald. Lete: arte e crítica do esquecimento. Rio de Janeiro: Civilização Brasileira, 2001.

WAGNER, Roy. A invenção da cultura. São Paulo: Cosac\&Naif, 2010. 